\title{
ANÁLISE DE STAKEHOLDERS EM INDÚSTRIA DO SETOR PLÁSTICO: UMA APLICAÇÃO DA NORMA ABNT NBR ISO 14001:2015
}

\author{
Flavia Cristina Silva \\ Doutoranda em Administração \\ Universidade Presbiteriana Mackenzie São Paulo - SP - Brasil \\ flacrisil@yahoo.com.br https://orcid.org/0000-0001-6999-948X \\ Fabio Ytoshi Shibao \\ Doutor em Administração \\ Universidade Nove de Julho - Uninove São Paulo - SP - Brasil \\ fabio.shibao@gmail.com http://orcid.org/0000-0002-6666-0330 \\ Mario Roberto dos Santos \\ Doutor em Administração \\ Universidade Nove de Julho - Uninove São Paulo - SP - Brasil \\ mario.rsantos@terra.com.br http://orcid.org/0000-0001-6222-9255 \\ José Carlos Barbieri \\ Doutor em Administração \\ Fundação Getúlio Vargas - FGV São Paulo - SP - Brasil \\ jose.barbieri@fgv.br http://orcid.org/0000-0002-4019-8950
}

\section{RESUMO}

A última revisão da norma ISO 14001 sobre Sistemas de Gerenciamento Ambiental (SGA) incluiu a obrigatoriedade de que a organização reconheça as partes interessadas (stakeholders) em seu desempenho ambiental. Este estudo teve como objetivo identificar os stakeholders e hierarquizar sua influência sobre o desempenho ambiental de uma indústria de transformação de material plástico. Utilizou-se a abordagem de métodos mistos e dividiu-se a pesquisa em duas fases. A fase qualitativa consistiu na realização da pesquisa-ação e emprego da técnica de grupo focal para identificação dos stakeholders e suas necessidades e expectativas, e, em seguida, sua classificação. A fase qualitativa empregou o método AHP para a hierarquização dos stakeholders. No que concerne aos tipos de stakeholders, foram identificadas quatro classes: definitivos, dependentes, dominantes e facultativos e, dentre esses, cerca de $50 \%$ foram classificados como primários por exercerem influência direta sobre decisões e atividades da empresa. Em relação à prioridade de interesses, constatou-se que proprietários, clientes e órgãos governamentais receberam a atenção primária, enquanto a comunidade de entorno e os grupos ambientais ocuparam a posição menos relevante. As contribuições teórica e prática do estudo consistem, respectivamente, em um modelo de identificação e classificação dos stakeholders para o setor de transformação de material plástico e uma ferramenta de planejamento do SGA.

Palavras-chave: ABNT NBR ISO 14001. Analytic hierarchy process (AHP); Sistema de gestão ambiental. Stakeholder.

\section{ANALYSIS OF STAKEHOLDERS IN THE PLASTIC INDUSTRY: AN APPLICATION OF ABNT NBR ISO 14001: 2015}

\section{ABSTRACT}

The review of ISO 14001 on Environmental Management Systems (EMS) included the obligation for the organization to recognize stakeholders in their environmental performance. This study aimed to identify the stakeholders and hierarchize their influence over the environmental performance of a plastic material processing industry. The mixed methods approach was used and the research was divided into two phases. The qualitative phase consisted in performing the action research and the use of the focal group technique to identify the stakeholders and their needs and expectations, and then their classification. The qualitative phase used the AHP method for the hierarchy of stakeholders. Concerning the types of stakeholders, four classes were identified: definitive, dependent, dominant and facultative, of which $50 \%$ were classified as primary because they had a direct influence on decisions and activities of the company. Regarding the priority of interests, it was found that owners, customers and government agencies received primary attention, while the surrounding community and environmental groups occupied the least relevant position. The theoretical and practical contributions of the study consist, respectively, of a stakeholder identification and classification model for the plastic material transformation sector and an EMS planning tool.

Key words: ABNT NBR ISO 14001. Analytic hierarchy process (AHP). Environmental management system. Stakeholder.

Data da submissão: 09/10/2018

Data de aceite: 09/01/2020 


\section{INTRODUÇÃO}

A sociedade atual exige alto padrão de vida, o que implica consumo crescente de produtos e serviços, e a entrega desses requer o emprego de grandes quantidades de recursos com emissão simultânea de poluentes. A consciência a respeito dos impactos significativos do consumo sobre o meio ambiente, tais como os efeitos sobre o clima, a biodiversidade e a saúde humana (Rosa, Guesser, Hein, Pfitscher, \& Lunkes, 2015), tem crescido tanto entre os próprios consumidores, como entre legisladores e empresas. Consumidores desejam que suas aquisições incluam escolhas ambientais corretas, enquanto legisladores pretendem que as leis orientem a produção e o consumo sustentáveis ante os desafios ambientais globais de preservação do meio ambiente (Carvalho, Mimoso, Mendes, \& Matos, 2014).

As duas últimas décadas foram marcadas pelo desenvolvimento e pela difusão de muitas normas ambientais. Por meio desses regulamentos privados ou não-governamentais, as empresas se comprometem a melhorar voluntariamente suas práticas de gerenciamento ambiental, entre eles, está a norma da International Organization for Standardization (ISO, 2017) de gestão ambiental ISO 14001 (Milazzo et al., 2017).

Esse tipo de certificação também é usado pelas empresas para aumentar a confiança dos stakeholders. Um objetivo comum de muitas organizações é ser capaz de respeitar os padrões da família ISO 14000 e combinar produtividade e lucro com o gerenciamento ambiental (Milazzo et al., 2017).

A norma ISO 14001, publicada pela primeira vez em 1996, determina um sistema de gestão ambiental (SGA) genérico que tem como objetivo o alcance da conformidade ambiental institucional e que pode ser aplicado por qualquer organização, independentemente de seu processo, cultura, escala e localização geográfica (Pryshlakivsky \& Searcy, 2013; Salim et al., 2018; Tien, Chung, \& Tsai, 2002). Essa norma se concentra especificamente em maneiras de implementar um sistema de gerenciamento e manter as responsabilidades ambientais da empresa (Milazzo et al., 2017).

O Sistema de Gestão Ambiental da ISO 14001 destaca-se entre aqueles utilizados para gestão de aspectos e processos ambientais corporativos (Oliveira, Oliveira, Ometto, Ferraudo, \& Salgado, 2016), por fornecer uma diretriz para as organizações realizarem uma melhoria contínua no seu desempenho ambiental e serve para demonstrar o comprometimento organizacional com processos de produção sustentáveis (Salim et al., 2018).

Pouco tempo depois da publicação da primeira versão da norma ISO 14001, ao avaliar a importância atribuída às partes interessadas, ou stakeholders, por empresas com diferentes níveis de comprometimento ambiental, Henriques e Sadorski (1999) constataram a tendência de empresas proativas envolverem os interesses de diversos grupos em suas atividades, enquanto as empresas menos comprometidas ambientalmente apresentaram-se resistentes à participação de seus stakeholders.

A terceira revisão da norma ISO 14001, publicada em 2015, prevê que a organização adquira a compreensão geral das necessidades e expectativas dos stakeholders e determine quais dessas, sejam obrigatórias ou voluntárias, serão adotadas, conforme a Associação Brasileira de Normas Técnicas (ABNT, 2015a). A nova ISO 14001:2015 foi criada pelas necessidades do mercado, como forma de abordar a economia circular e a sustentabilidade industrial (Milazzo et al., 2017). Conforme a ISO (2017), até o ano de 2016 inclusive, foram computadas 346.189 certificações.

Um SGA padronizado aumenta o controle interno do custo de introdução de algum grau de rigidez no cuidado ambiental de suas operações. Embora a maioria das empresas apresente-se resistente aos investimentos iniciais e ao aumento do custo das operações, é consenso tanto entre empresas de países desenvolvidos (Birou, Green \& Inman, 2019) como entre as nacionais, que, a longo prazo, um SGA contribui para o aumento de eficiência operacional, economia de recursos e proteção contra sanções e multas. Empresas que possuem políticas ambientais severas tendem a

Revista de Gestão Social e Ambiental - RGSA, São Paulo, v. 13, n. 2, p. 40-57, maio/ago. 2019. 
implementar sistemas de gestão padronizados, e, por consequência, a concentrar seus esforços na redução dos impactos ambientais.

Para Alonso-Paulı e André (2015), embora esse tipo esforço resulte em menor poluição, apenas se os incentivos públicos forem suficientemente fortes, esses sugerem uma relação de complementaridade entre o SGA padronizado e as políticas públicas.

Influenciadas não somente por normas e leis governamentais, mas também por outros stakeholders, tais como as associações comerciais, os empregados, os moradores do entorno, entre outros, as empresas têm adotado práticas de gestão ambiental para minimizar os impactos ambientais de suas atividades (Dhull \& Narwal, 2016). Como é o caso da pressão exercida pelos clientes como um forte direcionador para a implementação de políticas ambientais, tal como ocorre na indústria automotiva, especialmente em relação aos fornecedores de primeira camada. Nesse contexto, este estudo teve como objetivo identificar os stakeholders e hierarquizar seus interesses em relação ao desempenho ambiental de uma indústria de transformação de material plástico.

Outras cinco seções são apresentadas além desta breve introdução: a fundamentação teórica desta pesquisa é exposta na seção dois e a caracterização do setor estudado na seção três. A quarta seção apresenta os procedimentos metodológicos e a quinta seção contém os resultados confrontados à luz da teoria. Na sexta seção, encerram-se com as considerações finais e sugestões para futuros trabalhos.

\section{FUNDAMENTAÇÃO TEÓRICA}

Debates sobre a importância da gestão ambiental organizacional têm se intensificado no contexto das organizações, com o decorrente aumento na adoção de práticas de gestão ambiental. A efetiva implementação de tais práticas, no entanto, requer uma série de pré-requisitos responsáveis pela "ecologização" das organizações, tais como aspectos humanos e operacionais (Jabbour, Jugend, Jabbour, Gunasekaran, \& Latan, 2015).

De acordo com Barbieri (2007), a gestão ambiental pode ser compreendida como o conjunto de diretrizes operacionais e administrativas que visam a obtenção de efeitos positivos sobre o meio ambiente, por meio da prevenção, redução ou mitigação dos danos resultantes das atividades humanas.

A melhoria do desempenho ambiental pode ser definida como uma redução dos impactos negativos que uma empresa possa causar ao meio ambiente. Em sentido restrito, consiste na redução ou eliminação das emissões e dos resíduos, e, em sentido amplo, engloba a escolha das matériasprimas e o consumo de recursos, as formas de uso do produto e os métodos de descarte (Tien et al., 2002).

Organizações que interpretam a poluição, não apenas como uma consequência indesejável de seu processo, e inserem as questões ambientais em seu modelo de gestão têm obtido maior visibilidade. Nesse sentido, a certificação dos Sistemas de Gestão Ambiental (SGA) consiste em um meio que as empresas encontraram para assumir publicamente sua preocupação com a questão ambiental e lidar com as demandas conscientes dos mercados e dos consumidores (Campos, 2012).

Conforme Alberton (2003, p. 20) "[...] a implantação de um sistema de gestão ambiental faz com que o processo produtivo seja reavaliado e reflita a busca por procedimentos, mecanismos, arranjos e padrões menos nocivos ao meio ambiente". Estruturar o SGA de acordo com a norma da ABNT NBR ISO 14001 permite a uma organização considerar requisitos legais e informações referentes aos impactos ambientais significativos na formulação de sua política e objetivos (Campos, 2012).

As organizações têm buscado a certificação de seus sistemas de gestão ambiental, pois, segundo Wiengarten, Pagell e Fynes (2013), a certificação destina-se a proporcionar uma abordagem estratégica global da política ambiental empresarial, de seus planos e ações.

Segundo a norma ABNT NBR ISO 14001:2015, o objetivo de um sistema de gestão ambiental é "[...] prover as organizações uma estrutura para a proteção do meio ambiente e 
possibilitar uma resposta às mudanças das condições ambientais em equilíbrio com as necessidades socioeconômicas" (ABNT, 2015b, viii).

A Figura 1 compara os modelos de SGA propostos nas duas últimas revisões da norma ABNT NBR ISO 14001 e mostra a evolução das abordagens.

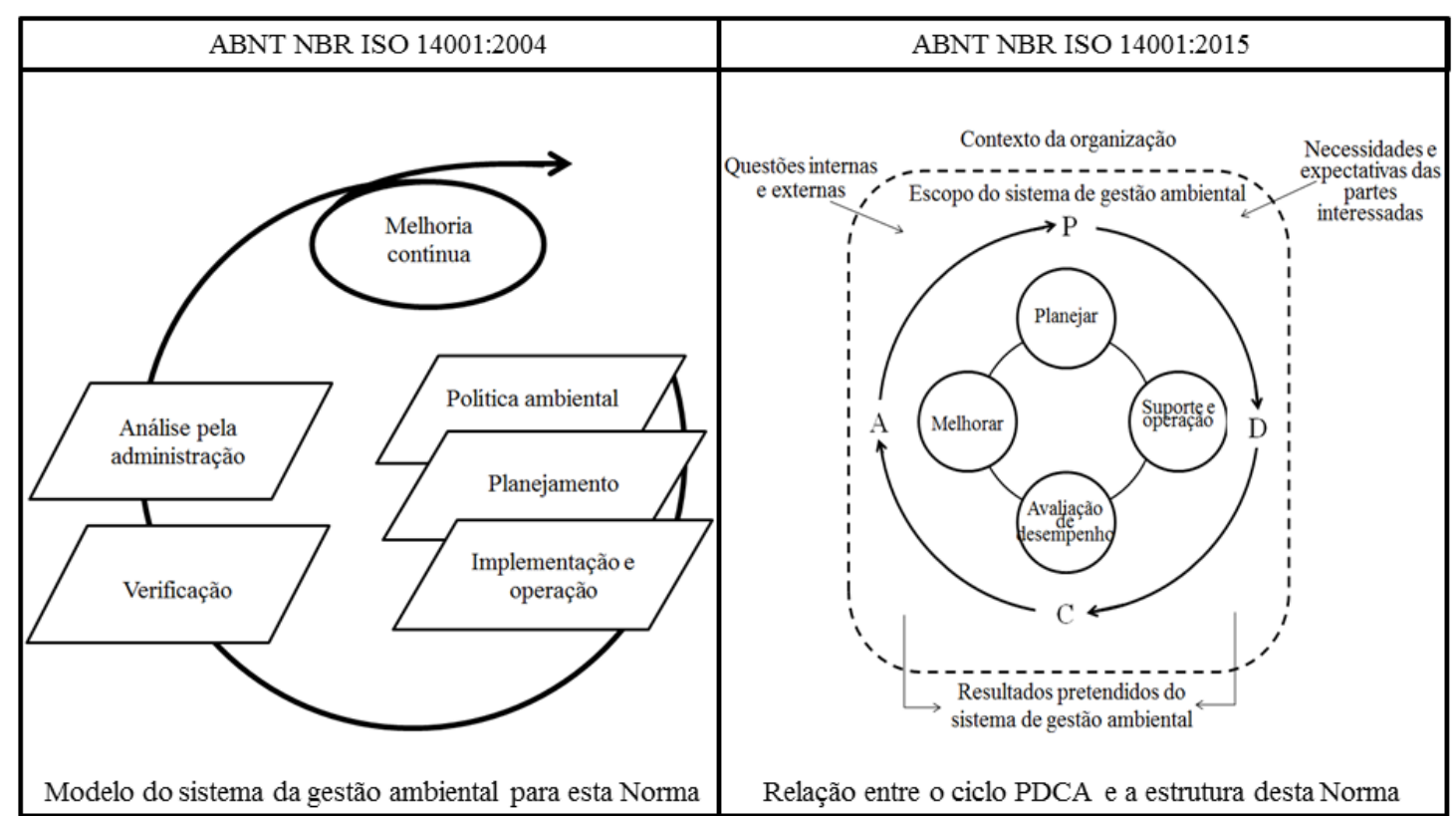

Figura 1 - Evolução do conceito de abrangência do sistema de gestão ambiental Fonte: ABNT $(2004,2015 a)$

Nota-se que a ampliação do objetivo da norma, que, em 2004, consistia em prover à organização uma estrutura para a proteção do meio ambiente, a partir da inclusão da perspectiva social por meio dos termos "necessidades socioeconômicas".

A comparação dos esquemas das duas versões sugere que as fronteiras das empresas deixaram de ser rigidamente delimitadas e passam a permitir a integração com o meio ambiente, o que se justifica pelo fato de que, embora a degradação possa ser localizada, seus efeitos e consequências podem ser disseminados a grandes distâncias. Entre os exemplos do efeito globalizado da degradação ambiental estão o aquecimento global, a elevação do nível dos oceanos, a alteração do regime de chuvas e desertificação. A Figura 2 detalha as principais diferenças entre as revisões 2004 e 2015. 
Flavia Cristina Silva, Fabio Ytoshi Shibao, Mario Roberto dos Santos, José Carlos Barbieri

\begin{tabular}{|c|c|c|}
\hline Itens & 2004 & 2015 \\
\hline Objetivo da norma & $\begin{array}{l}\text { Prover as organizações de elementos de um } \\
\text { sistema da gestão ambiental (SGA) eficaz que } \\
\text { possam ser integrados a outros requisitos da } \\
\text { gestão, e auxiliá-las a alcanças seus objetivos } \\
\text { ambientais e econômicos. }\end{array}$ & $\begin{array}{l}\text { Prover as organizações uma estrutura para a proteção do } \\
\text { meio ambiente e possibilitar uma resposta às mudanças } \\
\text { das condições ambientais em equilíbrio com as } \\
\text { necessidades socioeconômicas. }\end{array}$ \\
\hline $\begin{array}{l}\text { Conceito PDCA aplicado ao } \\
\text { SGA }\end{array}$ & $\begin{array}{l}\text { Planejar: estabelecer os objetivos e processos } \\
\text { necessários para atingir os resultados em } \\
\text { concordância com a política ambiental da } \\
\text { organização; Executar: implementar os } \\
\text { processos; Verificar: monitorar e medir os } \\
\text { processos em conformidade com a política } \\
\text { ambiental, objetivos, metas, requisitos legais e } \\
\text { outros, e relatar os resultados; Agir: agir para } \\
\text { continuamente melhorar o desempenho dos } \\
\text { sistema de gestão ambiental. }\end{array}$ & $\begin{array}{l}\text { Planejar: estabelecer os objetivos ambientais e os } \\
\text { processos necessários para entregar resultados de } \\
\text { acordo com a política ambiental da organização; } \\
\text { Executar: implementar os processos conforme planejado; } \\
\text { Checar: monitorar e medir os processos em relação à } \\
\text { política ambiental, incluindo seus compromissos, } \\
\text { objetivos ambientais e critérios operacionais, e reportar } \\
\text { os resultados; Agir: tomar ações para melhoria contínua. }\end{array}$ \\
\hline Sistema de gestão & $\begin{array}{l}\text { É um conjunto de elementos inter-relacionados } \\
\text { utilizados para estabelecer a política e objetivos } \\
\text { e para atingir esse objetivos. Inclui estrutura } \\
\text { organizacional, atividade de planejamento, } \\
\text { responsabilidade, práticas, procedimentos, } \\
\text { processos e recursos. }\end{array}$ & $\begin{array}{l}\text { É o conjunto de elementos inter-relacionados ou } \\
\text { interativos de uma organização para estabelecer políticas, } \\
\text { objetivos e processos para alcançar esses objetivos. } \\
\text { Pode abordar uma única disciplina ou várias disciplinas } \\
\text { (gestãao da qualidade, gestão ambiental, gestão da saúde } \\
\text { e segurança ocupacional, gestão da energia, gestão } \\
\text { financeira etc.). Incluema estrutura da organização, papéis } \\
\text { e responsabilidades, palenjamento e operação, avaliação } \\
\text { de desempenho e melhoria. O escopo pode incluir a } \\
\text { totalidade da organização, funções especificas e } \\
\text { identificadas da organização, seções especificas e } \\
\text { identificadas da organização, ou uma ou mais funções } \\
\text { dentro de um gurpo de oraganizações. }\end{array}$ \\
\hline Sistema de gestão ambiental & $\begin{array}{l}\text { Parte de um sistema da gestão de uma } \\
\text { organização utilizada para desenvolver e } \\
\text { implementar sua política ambiental e para } \\
\text { gerenciar aspectos ambientais. }\end{array}$ & $\begin{array}{l}\text { Parte do sistema de gestão usado para gerenciar aspectos } \\
\text { ambientais, cumprir requisitos legais e outros requisitos, } \\
\text { e abordar riscos e oportunidades. }\end{array}$ \\
\hline Objetivo ambiental & $\begin{array}{l}\text { Propósito ambiental geral, decorrente } \text { da } \\
\text { política ambiental que uma organização se } \\
\text { propõe a atingir. }\end{array}$ & $\begin{array}{l}\text { Objetivo definido pela organização, coerente com a sua } \\
\text { política ambiental. }\end{array}$ \\
\hline
\end{tabular}

Figura 2 - Comparação entre as normas

Fonte: ABNT (2004, 2015a)

Na visão de Milazzo et al. (2017), a nova versão da norma ISO 14001 incluiu as melhorias, tais como um melhor desempenho ambiental relacionado a ações proativas; um maior nível de envolvimento da alta administração; maior especificidade na análise do ciclo de vida; pensamento voltado ao risco e uma melhor estratégia de comunicação.

Em relação aos termos utilizados na versão anterior, a norma ABNT NBR ISO14001:2015 alterou e expandiu as definições como no caso de: informação documentada; alta direção; auditoria. Exemplos de termos inseridos são: ciclo de vida; condição ambiental; risco; parte interessada; terceirizar. A contextualização desses termos denota a intenção de que as organizações estejam comprometidas com seu produto em todas as fases, antes e depois da fabricação, bem como é ampliada a responsabilidade e incentivada a postura proativa com a inserção da noção de risco ambiental.

Dentre os termos excluídos na nova versão, estão: auditor; documento; meta ambiental; auditoria interna; ação preventiva; procedimento; registro documentado (ABNT, 2015a). A nova versão busca enfatizar o caráter cíclico dos conceitos e atividades, priorizando a complementaridade das operações para o funcionamento do sistema.

A norma define parte interessada (stakeholder) como: "[...] pessoa ou organização que pode afetar, ser afetada ou se perceber afetada por uma decisão ou atividade. Cita como exemplos: clientes, comunidades, fornecedores, regulamentadores, organizações não governamentais, investidores e funcionários" (ABNT, 2015a, p.2).

Dragomir (2013) expandiu sua visão ao considerar como stakeholders todos os atores que tenham participação nas atividades da empresa: sindicatos, organizações não-governamentais (ONGs), ativistas, famílias vizinhas, concorrentes, financiadores que não sejam acionistas, analistas, mídia, profissionais contábeis, associações industriais, autoridades fiscais, partidos políticos, 
especialistas, acadêmicos e artistas. Como discutido anteriormente em relação aos efeitos da poluição, em se tratando da questão ambiental, uma parte interessada não pode ser geograficamente delimitada, visto que os impactos ambientais podem se alastrar no ambiente.

A interpretação atual que se tem sobre o conceito stakeholder evoluiu da definição seminal de Freeman (1984), que caracterizou como parte interessada qualquer indivíduo que possa afetar ou ser afetado pela realização de um propósito corporativo, de maneira que a ideia de que as corporações têm stakeholders tornou-se comum na literatura de gestão empresarial, tanto acadêmica quanto profissional (Donaldson \& Preston, 1995).

Os stakeholders podem ser classificados em três grupos, segundo Curzon (2009):

a) Primários: Grupos com alto nível de poder, envolvimento e influência em todas as etapas do processo, desde os estágios iniciais até a conclusão. Capacidade de influenciar diretamente o processo de tomada de decisão, o resultado e outros grupos de partes interessadas de nível inferior.

b) Secundários: Os grupos têm alguma capacidade de influenciar o processo de tomada de decisão, mas é provável que tenha se envolvido após decisões importantes já terem sido tomadas. As partes interessadas secundárias provavelmente estarão ativamente envolvidas no gerenciamento local e no projeto e terão alguma capacidade de influenciar ou escolher envolver grupos de partes interessadas de nível inferior. As partes interessadas secundárias incluem: órgãos nacionais de meio ambiente, patrocinadores corporativos etc.

c) Terciários: Os grupos não estão diretamente envolvidos no processo de tomada de decisões, nem podem influenciá-las diretamente. Geralmente, recorre à atuação por meio de outros grupos de partes interessadas de alto nível para que as suas reivindicações sejam ouvidas. É provável que esse grupo seja informado de decisões, mas não esteja envolvido ativamente no processo de tomada de decisões ou no gerenciamento local. Estes grupos terciários podem intervir quando as partes interessadas de nível superior precisam de orientação especializada local ou de especialização para um problema específico. Esse grupo pode ser visto como um incômodo ou uma interferência que deverá ser gerenciado.

As organizações enfrentam ambientes ambíguos, complexos e em constante mudança, de tal modo que as interações com os stakeholders se tornaram uma questão crítica para os gestores e oferecem, ao mesmo tempo, tanto desafios quanto oportunidades ( $\mathrm{Wu}, 2012)$.

\section{CARACTERIZAÇÃO DO SETOR PLÁSTICO BRASILEIRO}

No primeiro nível ou geração da cadeia produtiva do setor de plástico, à montante, a nafta derivada do refino de petróleo é transformada em insumos petroquímicos, tais como etileno e propeno. A geração seguinte polimeriza os compostos químicos em resinas termo plásticas que serão utilizadas como matérias-primas pelas indústrias de transformação da terceira geração. À jusante, encontram-se varejistas e consumidores, conforme se observa na Figura 3 (Bastos, 2009; Moreira et al., 2010; Padilha \& Bomtempo, 1999).

O setor petroquímico caracteriza-se como um oligopólio devido a sua estrutura condensada em um reduzido número de indústrias de primeira e segunda geração, que possuem relevante poder de mercado, realizam investimentos em valores expressivos e apresentam barreiras à entrada (Bastos, 2009).

Em contrapartida, o setor de transformados plásticos possui estrutura pulverizada e heterogênea, que não oferece barreiras à entrada e realiza investimentos modestos (Moreira et al., 2010). Conforme Silva, Costa, Pereira e Costa (2013), a dessemelhança entre os níveis pode ser mais bem evidenciada pela comparação de investimentos necessários à geração de empregos diretos em cada geração: aproximadamente R\$ 10 milhões na indústria petroquímica e R\$ 1 milhão no setor de transformação.

A maioria das empresas que compõe o setor de transformados por porte de pessoal ocupado de 2016 , foi classificada em micro $(73,4 \%)$ e pequenas empresas $(20,9 \%)$, conforme a Associação Brasileira da Indústria do Plástico (Abiplast, 2017). 


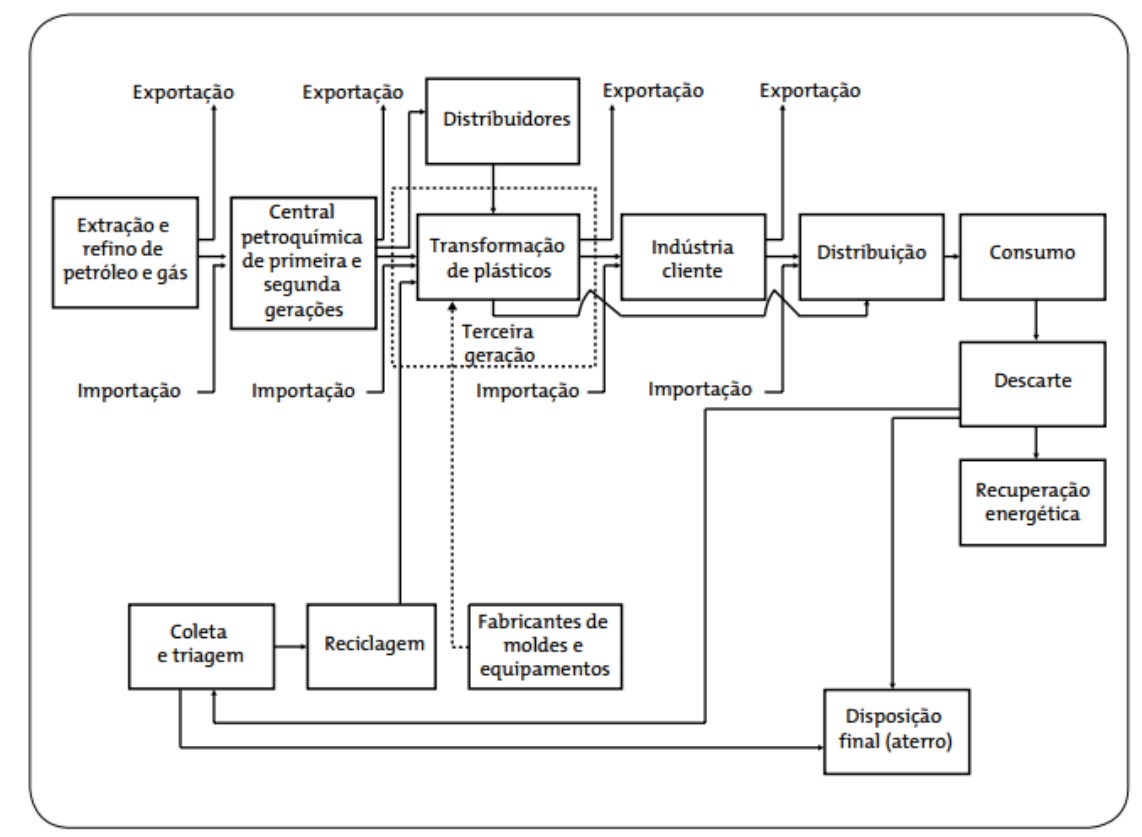

Figura 3 - Cadeia produtiva da transformação de plásticos Fonte: Silva et al. (2013)

Dentre os processos produtivos dos transformados plásticos, destacam-se a extrusão e a injeção, responsáveis respectivamente por cerca de $55 \%$ e $36 \%$ da produção total. Outros meios comuns de transformação são os processos de injeção sopro, rotomoldagem e termoformação a vácuo, enquanto a reciclagem dos produtos plásticos pode ocorrer por processo mecânico, químico e/ou térmico, segundo a Abiplast (2017) e o Sindicato da Indústria de Material Plástico do Estado de São Paulo (Sindiplast, 2011).

A fabricação de produtos plásticos consome, além das resinas, insumos como aditivos químicos, pigmentos, cargas minerais, elastômeros, insertos metálicos, lubrificantes, fluídos térmicos e lubrificantes, entre outros. Os equipamentos utilizados nas várias etapas de processo possuem elevada potência e consomem grande quantidade de energia, em contrapartida, obtém-se economia no consumo de água por meio de sistemas de circulação em circuito fechado para trocas de calor e resfriamento das peças (Sindiplast, 2011; Silva et al., 2013).

A respeito dos aspectos ambientais decorrentes da transformação de plásticos, observa-se a prevalência do consumo de recursos, emissões atmosféricas, descarte de efluentes e descarte de resíduos sólidos (Sindiplast, 2011). Quanto aos potenciais impactos, o estudo de caso realizado por Silva, Shibao e Santos (2015) em uma indústria de transformados plásticos identificou 25 potenciais impactos, dentre eles a redução de disponibilidade de recursos naturais, a poluição do ar e a contaminação do solo e de águas superficiais.

\subsection{Perfil da indústria pesquisada}

Situada na região metropolitana de São Paulo, a empresa Alfa atua há 50 anos na fabricação de artefatos plásticos para o mercado de utilidades domésticas, embalagens e peças automotivas. Atualmente, possui 720 colaboradores diretos e ocupa cerca de $74 \%$ da capacidade instalada, o que resulta na transformação diária de 65 toneladas de matéria-prima por meio dos processos de sopro e injeção. Seu sistema de gestão ambiental foi certificado em 2007, conforme a norma Abnt NBR ISO 14001:2004, e este estudo foi aplicado como medida para a adequação à nova versão da norma. 


\section{MÉTODO DE PESQUISA}

Esta pesquisa se dedicou ao delineamento do tema, uma vez considerado o intuito de produzir conhecimento e propor um modelo a ser utilizado na solução de problemas específicos, razões pelas quais pode ser classificada como exploratória quanto aos seus objetivos, e aplicada em relação à sua natureza (Prodanov \& Freitas, 2013).

Sob o ponto de vista da abordagem do problema, este estudo emprega métodos mistos. A Figura 4 ilustra a adaptação da estratégia exploratória sequencial descrita por Creswell (2010, p. 248) aos objetivos propostos. Observa-se, pela descrição e nomenclatura do modelo (QUAL/quan), que os dados quantitativos servem para maior compreensão dos resultados qualitativos, razão que justifica a ênfase dada à primeira fase, destinada à exploração do fenômeno (Creswell, 2010; Duarte, 2009).

Em relação aos procedimentos técnicos adotados, a fase qualitativa foi norteada pela pesquisa-ação, que contou com a interação entre pesquisadores e representantes da organização e o emprego de diversas técnicas de pesquisa (Thiollent, 2007, p. 16, 28), e a fase qualitativa, pelo uso do método AHP.

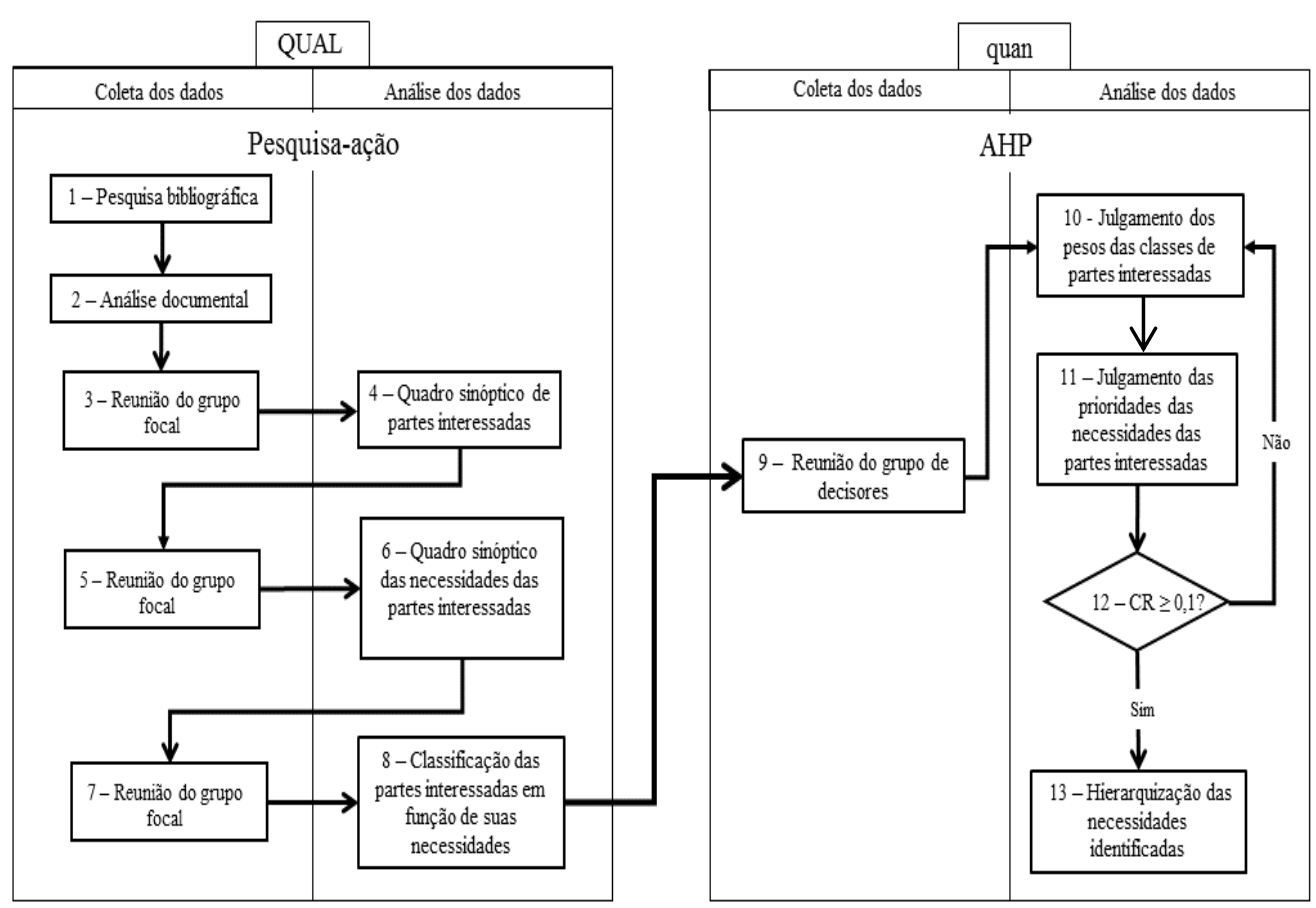

Figura 4 - Fluxograma de pesquisa

Fonte: Elaborado pelos autores

Etapa 1

Consistiu na identificação de teorias e modelos aplicáveis à solução da situação problema por parte dos pesquisadores.

Etapa 2

Demandou a análise de procedimentos, instruções de trabalho e registros ambientais para seleção das áreas com vínculos significativos em número de atribuições e responsabilidade ao SGA da empresa Alpha, para convocação dos participantes do projeto.

Etapas 3 a 8

As reuniões do grupo focal consistiram no confronto das colocações por meio de debates moderados, orientados pelo roteiro semiestruturado apresentado na Figura 5 a seguir. 
Flavia Cristina Silva, Fabio Y toshi Shibao, Mario Roberto dos Santos, José Carlos Barbieri

\begin{tabular}{|c|c|c|c|c|c|}
\hline \multirow{5}{*}{ 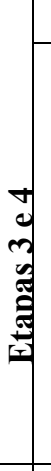 } & \multirow[t]{2}{*}{ Objetivo } & \multirow[b]{2}{*}{ Características } & \multicolumn{2}{|r|}{ Critérios } & \multirow{2}{*}{ Referências } \\
\hline & & & & Descrição & \\
\hline & \multirow{3}{*}{$\begin{array}{l}\text { Identificar as } \\
\text { partes } \\
\text { interessadas no } \\
\text { desempenho } \\
\text { ambiental da } \\
\text { organização }\end{array}$} & Poder $[\mathrm{Po}]$ & $\begin{array}{l}\text { A parte interessa } \\
\text { de força para in } \\
\text { controle e restr } \\
\text { financeiros e ima }\end{array}$ & $\begin{array}{l}\text { a dispõe de meios normativos ou } \\
\text { or sua vontade ou condições de } \\
\text { ão de bens materiais, recursos } \\
\text { em, entre outros. }\end{array}$ & \multirow{3}{*}{$\begin{array}{l}\text { Mitchell, } \\
\text { Agle, \& } \\
\text { Wood (1997) }\end{array}$} \\
\hline & & $\begin{array}{l}\text { Legitimidade } \\
\text { [Le] }\end{array}$ & \multicolumn{2}{|c|}{$\begin{array}{l}\text { A participação da parte interessada é reconhecida } \\
\text { por outros, além dela mesma. }\end{array}$} & \\
\hline & & Urgência [Ur] & \multicolumn{2}{|c|}{$\begin{array}{l}\text { A parte interessada requer alto grau de atenção às } \\
\text { suas reinvindicações. }\end{array}$} & \\
\hline \multirow{3}{*}{ 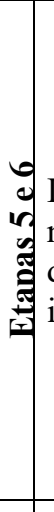 } & \multirow{3}{*}{$\begin{array}{l}\text { Identificar as } \\
\text { necessidades } \\
\text { das partes } \\
\text { interessadas }\end{array}$} & Foco & \multirow{2}{*}{\multicolumn{2}{|c|}{$\begin{array}{l}\text { Redução de custos da conformidade ou não } \\
\text { conformidade com a legislação; redução de custos } \\
\text { com disposição final de resíduos e controle da } \\
\text { poluição; investimentos relacionados ao desempenho } \\
\text { ambiental; potenciais vantagens derivadas da gestão } \\
\text { ambiental. }\end{array}$}} & \multirow{3}{*}{$\begin{array}{l}\text { ABNT } \\
(2015 b)\end{array}$} \\
\hline & & Financeiro $[\mathrm{F}]$ & & & \\
\hline & & Ambiental $[\mathrm{A}]$ & \multicolumn{2}{|c|}{$\begin{array}{l}\text { Prevenção e mitigação de impactos ambientais que } \\
\text { afetam a qualidade de vida, saúde e segurança e/ou a } \\
\text { biodiversidade, consumo de recursos e } \\
\text { sustentabilidade, entre outros. }\end{array}$} & \\
\hline \multirow{9}{*}{ 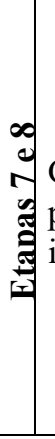 } & \multirow{9}{*}{$\begin{array}{l}\text { Classificar as } \\
\text { partes } \\
\text { interessadas }\end{array}$} & Relevância & Classificação & Característica presente & \multirow{9}{*}{$\begin{array}{c}\text { Mitchell, } \\
\text { Agle, \& } \\
\text { Wood (1997) }\end{array}$} \\
\hline & & \multirow{3}{*}{ Latente } & Dormente & Poder & \\
\hline & & & Facultativo & Legitimidade & \\
\hline & & & Exigente & Urgência & \\
\hline & & \multirow{3}{*}{ Moderada } & Dominante & Poder, legitimidade & \\
\hline & & & Perigoso & Poder, urgência & \\
\hline & & & Dependente & Urgência, legitimidade & \\
\hline & & Alta & Definitivo & Poder, legitimidade e urgência & \\
\hline & & Inexistente & Não relacionado & Não apresenta & \\
\hline
\end{tabular}

Figura 5 - Instrumento de moderação do grupo focal

Fonte: Elaborada pelos autores

Planejou-se debates com a presença de, no mínimo, um integrante de cada departamento. A gravação e transcrição do áudio de cada sessão deram origem a um quadro resumo utilizado como ponto de partida para a realização da reunião seguinte.

De acordo com Krueger e Casey (2000), o princípio do grupo focal não demanda, necessariamente, a votação ou consenso, mas consiste prioritariamente na identificação de padrões e tendências, neste caso, a identificação das partes interessadas no desempenho ambiental da empresa Alpha e suas necessidades.

Para a determinação dos requisitos a serem acatados e atendidos, conforme recomendação da norma Abnt NBR ISO 14001 (Abnt, 2015a, p.7), passou-se à aplicação do método AHP adaptado para a tomada de decisão em grupo, conforme Saaty e Vargas (2013), por meio da Agregação Individual de Julgamentos (AIJ), em que as prioridades são obtidas por meio de consenso ou votação (Dyer \& Forman, 1992; Saaty \& Peniwati, 2013).

Etapas 9 a 13

A quarta e última reunião destinaram-se ao julgamento das prioridades por meio de consenso ou maioria dos votos dos representantes que, inicialmente, decidiu sobre os pesos dos critérios, ou seja, sobre o peso das classes de stakeholders, e, em seguida, sobre as necessidades ou subcritérios, conforme é ilustrado na Figura 6. 


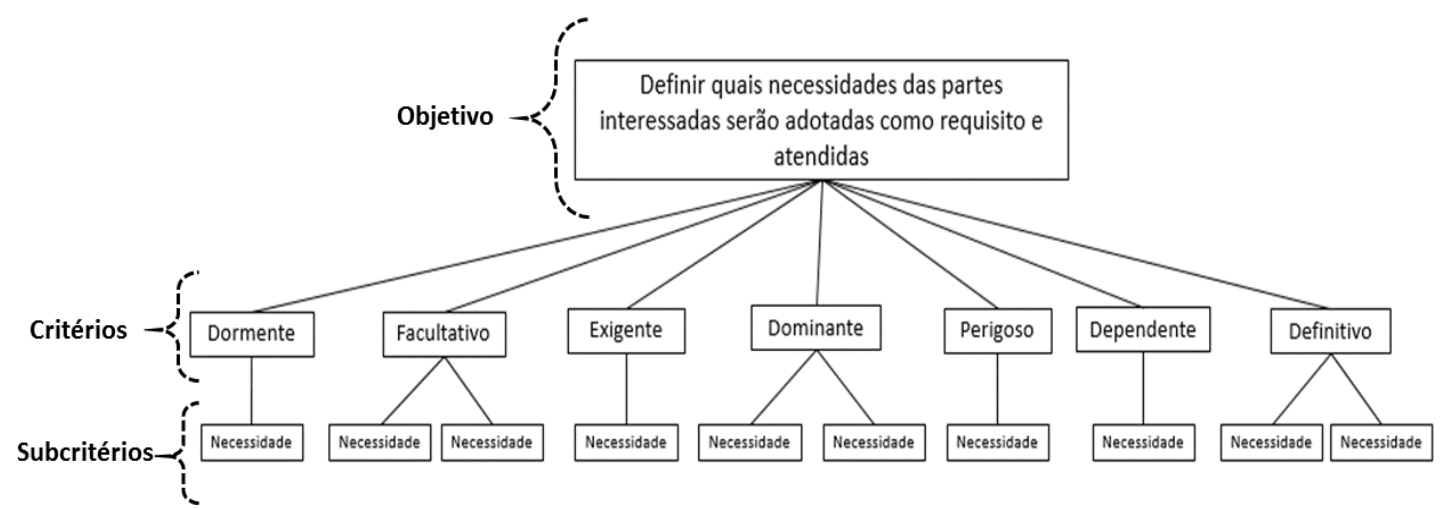

Figura 6 - Representação da hierarquia dos julgamentos pelo método AHP

Fonte: Elaborado pelos autores

A Etapa 10 consistiu em julgar a prioridade entre os tipos de stakeholder e na Etapa 11 julgou-se a prioridade entre os stakeholders de cada tipo, o que se conhece respectivamente como peso e prioridades relativas.

Utilizou-se a Escala Fundamental de Saaty com os seguintes índices para comparação: 1 para mesma importância entre os elementos; 3 para diferença moderada; 5 para diferença significativa; 7 quando um dos elementos é muito fortemente importante que outro, e 9 para diferenciar a importância extrema de um elemento sobre outro. Os valores 2, 4, 6 e 8 são considerados como intermediários entre dois julgamentos (Saaty \& Vargas, 2012).

A Etapa 12 serviu ao propósito de verificação da razão de consistência (Consistency Ratio [CR]) atingir valor igual ou menor que 0,1 (Saaty, 2013; Saaty \& Shang, 2011). Por fim, a Etapa 13 consistiu em obter as prioridades globais por meio do produto da multiplicação entre as prioridades relativas dos subcritérios e os pesos dos critérios.

\section{RESULTADOS DA PESQUISA, ANÁLISE E DISCUSSÃO DOS RESULTADOS}

Nesta apresentação dos resultados, primeiro será apresentada a fase qualitativa e, posteriormente, a fase quantitativa da pesquisa.

As atividades foram desenvolvidas entre os meses de maio e julho de 2016. Os departamentos de Compras, Jurídico, Recursos Humanos, Produção e Manutenção designaram, cada qual, um único representante que compareceu a todas as reuniões, e, dois funcionários do departamento de Qualidade. Ao final, todas as sessões foram realizadas com sete participantes.

Um dos autores atuou como moderador das reuniões do grupo focal e também como analista na reunião de aplicação do método AHP. No primeiro caso, utilizou-se o material avaliado na análise documental para estimular as discussões, sem que fosse exercido controle sobre as participações dos integrantes, conforme sugerido por Munaretto, Corrêa e Cunha (2013). No que se refere à aplicação do método AHP, o pesquisador limitou-se a transferir opiniões do grupo para a planilha da matriz de cálculo e tratar os dados com a objetividade recomendada por Gomes, Araya e Carignano (2004).

\section{Fase qualitativa}

A Figura 7 sumariza os resultados obtidos por meio do confronto das colocações nas reuniões do grupo focal. 


\begin{tabular}{|c|c|c|c|c|c|}
\hline \multirow{2}{*}{$\begin{array}{c}\text { Parte } \\
\text { interessada }\end{array}$} & \multicolumn{2}{|r|}{ Interesses } & \multirow{2}{*}{ Características } & \multirow{2}{*}{ Relevância } & \multirow{2}{*}{ Classificação } \\
\hline & Foco & Descrição & & & \\
\hline \multirow[b]{2}{*}{ Proprietários } & A & $\begin{array}{l}\text { Melhoria do desempenho ambiental dos } \\
\text { processos produtivos. }\end{array}$ & \multirow[b]{2}{*}{$\mathrm{P}_{\mathrm{o}} / \mathrm{L}_{\mathrm{e}} / \mathrm{U}_{\mathrm{r}}$} & \multirow[b]{2}{*}{ Alta } & \multirow{2}{*}{ Definitivo } \\
\hline & $\mathrm{F}$ & $\begin{array}{l}\text { Redução de custos com a gestão } \\
\text { ambiental; valorização da marca. }\end{array}$ & & & \\
\hline Colaboradores & A & $\begin{array}{l}\text { Proteção da saúde humana por meio de } \\
\text { melhoria da qualidade ambiental. }\end{array}$ & $\mathrm{L}_{\mathrm{e}} / \mathrm{U}_{\mathrm{r}}$ & Moderada & Dependente \\
\hline \multirow[b]{2}{*}{ Clientes } & A & $\begin{array}{l}\text { Melhoria do desempenho ambiental dos } \\
\text { processos produtivos. }\end{array}$ & \multirow[b]{2}{*}{$\mathrm{P}_{\mathrm{o}} / \mathrm{L}_{\mathrm{e}} / \mathrm{U}_{\mathrm{r}}$} & \multirow[b]{2}{*}{ Alta } & \multirow[b]{2}{*}{ Definitivo } \\
\hline & $\mathrm{F}$ & $\begin{array}{l}\text { Prevenção de custos pela } \\
\text { corresponsabilidade em infrações à } \\
\text { legislação ambiental, proteção e } \\
\text { valorização da marca. }\end{array}$ & & & \\
\hline $\begin{array}{l}\text { Instituições } \\
\text { financeiras }\end{array}$ & $\mathrm{F}$ & $\begin{array}{l}\text { Restituição de financiamentos, proteção } \\
\text { e valorização da marca. }\end{array}$ & $\mathrm{P}_{\mathrm{o}} / \mathrm{L}_{\mathrm{e}}$ & Moderada & Dominante \\
\hline Fornecedores & $\mathrm{F}$ & $\begin{array}{l}\text { Recuperação de investimentos em } \\
\text { melhorias do desempenho ambiental. }\end{array}$ & $\mathrm{L}_{\mathrm{e}}$ & Latente & Facultativo \\
\hline $\begin{array}{l}\text { Comunidade } \\
\text { do entorno }\end{array}$ & A & $\begin{array}{l}\text { Proteção da saúde humana por meio de } \\
\text { melhoria da qualidade ambiental }\end{array}$ & $\mathrm{L}_{\mathrm{e}} / \mathrm{U}_{\mathrm{r}}$ & Moderada & Dependente \\
\hline $\begin{array}{l}\text { Associações e } \\
\text { entidades de } \\
\text { classe }\end{array}$ & A & $\begin{array}{l}\text { Proteção da saúde humana por meio de } \\
\text { melhoria da qualidade ambiental. }\end{array}$ & $\mathrm{L}_{\mathrm{e}} / \mathrm{U}_{\mathrm{r}}$ & Moderada & Dependente \\
\hline $\begin{array}{l}\text { Associações } \\
\text { industriais }\end{array}$ & A & $\begin{array}{l}\text { Representação do setor perante a } \\
\text { sociedade e poder público. }\end{array}$ & $\mathrm{L}_{\mathrm{e}}$ & Latente & Facultativo \\
\hline \multirow[t]{2}{*}{$\begin{array}{l}\text { Órgãos } \\
\text { governamentais }\end{array}$} & A & $\begin{array}{l}\text { Regulamentação de parâmetros de } \\
\text { prevenção ou mitigação de impactos } \\
\text { ambientais com vistas à proteção da } \\
\text { saúde humana, recursos naturais e } \\
\text { biodiversidade. }\end{array}$ & \multirow[t]{2}{*}{$\mathrm{P}_{\mathrm{o}} / \mathrm{L}_{\mathrm{e}} / \mathrm{U}_{\mathrm{r}}$} & \multirow[t]{2}{*}{ Alta } & \multirow[t]{2}{*}{ Definitivo } \\
\hline & $\mathrm{F}$ & $\begin{array}{l}\text { Recolhimento de taxas e emolumentos } \\
\text { para manutenção de fundos de proteção } \\
\text { e defesa ambiental. }\end{array}$ & & & \\
\hline
\end{tabular}

Figura 7 - Mapeamento dos stakeholders e suas necessidades

Fonte: Elaborado pelos autores

Observou-se que as partes interessadas identificadas estão entre as categorias de stakeholders comumente citadas na literatura (Dragomir, 2013; Fonseca \& Domingues, 2018; Freeman, 1984). Nenhum dos stakeholders identificados apresentou as características determinadas para que fossem classificados como dormente, perigoso ou exigente. Essa característica é comum nos relacionamentos isentos de conflitos entre a empresa e suas partes interessadas, e pode ser vista por dois ângulos. A perspectiva favorável é que a negociação dos interesses conjuntos pode ser facilitada, o contraponto consiste na possibilidade de que os stakeholders sejam participados da condição ambiental da empresa após a tomada de decisão, o que seria danoso em caso de impacto.

A respeito da classificação das interações apresentadas pelos stakeholders (Curzon, 2009), notou-se que $50 \%$ corresponde à classe dos primários, ou seja, aqueles que influem diretamente nas decisões e atividades da empresa, são representados pelos proprietários, colaboradores, clientes, fornecedores e órgãos governamentais. Instituições financeiras, associações industriais, associações e entidades de classe juntos retratam $30 \%$ dos stakeholders e integram a classe secundária, daqueles que exercem influência indireta ou participam das decisões da organização a convite dos primários. Os $20 \%$ restantes se referem a comunidade do entorno e grupos ambientais locais, classificada como terciária devido ao baixo poder de influência, geralmente exercido por meio de representação ou intermediação de um stakeholder primário ou secundário.

Percebe-se, portanto, que na empresa Alpha a tomada de decisão referente aos assuntos ambientais ocorre predominantemente nas esferas internas da organização, contemplando mínima 
ou nenhuma participação dos stakeholders secundários e terciários. O baixo potencial poluidor da empresa pode ser apontado como uma das justificativas para a falta de mobilização da sociedade, muito embora não seja praxe a sociedade se comprometer voluntariamente com o monitoramento ambiental das empresas, exceto nos casos de acidentes que causem impactos como os de Mariana e Brumadinho, em Minas Gerais.

As discussões do grupo focal convergiram para reunir as partes interessadas de acordo com a similaridade de sua natureza e/ou interesses, a exemplo da categoria associações e entidades de classe, que envolveram desde sindicatos focados nas condições que afetam os colaboradores até institutos e organizações não-governamentais que objetivam o bem-estar social de toda comunidade.

Do mesmo modo, a classe órgãos governamentais reuniu representantes do poder público municipal e estadual, lotados na Coordenadoria Municipal de Vigilância Sanitária (Covisa) e a Agência Técnica Ambiental do Estado de São Paulo (Cetesb). Esse tipo de intervenção no setor privado não se caracteriza como uma ocorrência frequente, em geral por deficiência nos canais de comunicação e indisponibilidade de pessoal nos setores públicos, entre outros motivos. De acordo com a maioria dos participantes, a categorização das partes interessadas simplifica as operações de gestão de seus interesses, pelo fato de que a organização já emprega ferramentas de monitoramento de requisitos legais e levantamento de aspectos e impactos, bastando apenas associá-los às categorias identificadas.

Esse posicionamento contrasta com a colocação de Wolfe e Putler (2002), a respeito do caráter reducionista inerente à categorização das partes interessadas, uma vez que a heterogeneidade presente nos grupos não é evidenciada, tampouco reconhecida a multiplicidade de objetivos que caracterizariam as partes interessadas como pertencentes a dois ou mais grupos. Essas limitações e particularidades representam, segundo Sheehan e Ritchie (2005), a razão para que a empresa analise e classifique as relações mantidas com seus stakeholders e as priorize em sua gestão, nesse sentido a investigação realizada na empresa Alpha permitiu ressaltar a convergência dos interesses de seus múltiplos stakeholders.

\section{Fase quantitativa}

$\mathrm{Na}$ última reunião, os integrantes do grupo focal exerceram o papel de decisores e votaram pela prioridade dos stakeholders com base nos dados de relevância e classificação obtidos nas sessões anteriores.

Obteve-se, a princípio, com o julgamento da prioridade entre as categorias definitivo, dependente, dominante e facultativo, o peso de cada categoria. Em seguida, foram julgadas as prioridades entre os stakeholders alocados em cada categoria: i) Definitivos: proprietários, clientes e órgãos governamentais; ii) Dependentes: colaboradores, comunidade do entorno, associações e entidades de classe; iii) Facultativos: grupos ambientais e associações industriais; e iv) Dominantes: instituições financeiras e fornecedores.

De modo geral, houve consenso na maioria das votações. Houve divergência entre os decisores sobre a importância atribuída aos stakeholders do grupo dependentes, a nota de prioridade foi obtida por maioria de cinco dos sete votos. Foi identificado valor de CR igual a 0,151 , motivo pelo qual foi necessário que os participantes refizessem seus julgamentos a fim de que o novo cálculo do índice de consistência apresentasse valor menor que 0,1 , conforme recomendado por Saaty e Vargas (2012). Tais assimetrias são comuns entre grupos heterogêneos, além disso, as inconsistências podem ser originadas por falta de familiaridade com o método.

Procedeu-se nova votação e o novo índice RC alcançado foi de 0,031 . Para o grupo dos definitivos, o CR foi de 0,037 e para os grupos facultativos e dominantes não houve necessidade de calcular a consistência, pois, conforme Saaty e Vargas (2013), o cálculo da razão de consistência não se aplica quando as comparações ocorrem entre dois elementos.

As prioridades de cada stakeholder foram multiplicadas pelo peso da categoria a que pertencem e, desta forma, obteve-se a prioridade total de cada um. A hierarquia de prioridades é apresentada na Figura 8.

Revista de Gestão Social e Ambiental - RGSA, São Paulo, v. 13, n. 2, p. 40-57, maio/ago. 2019. 


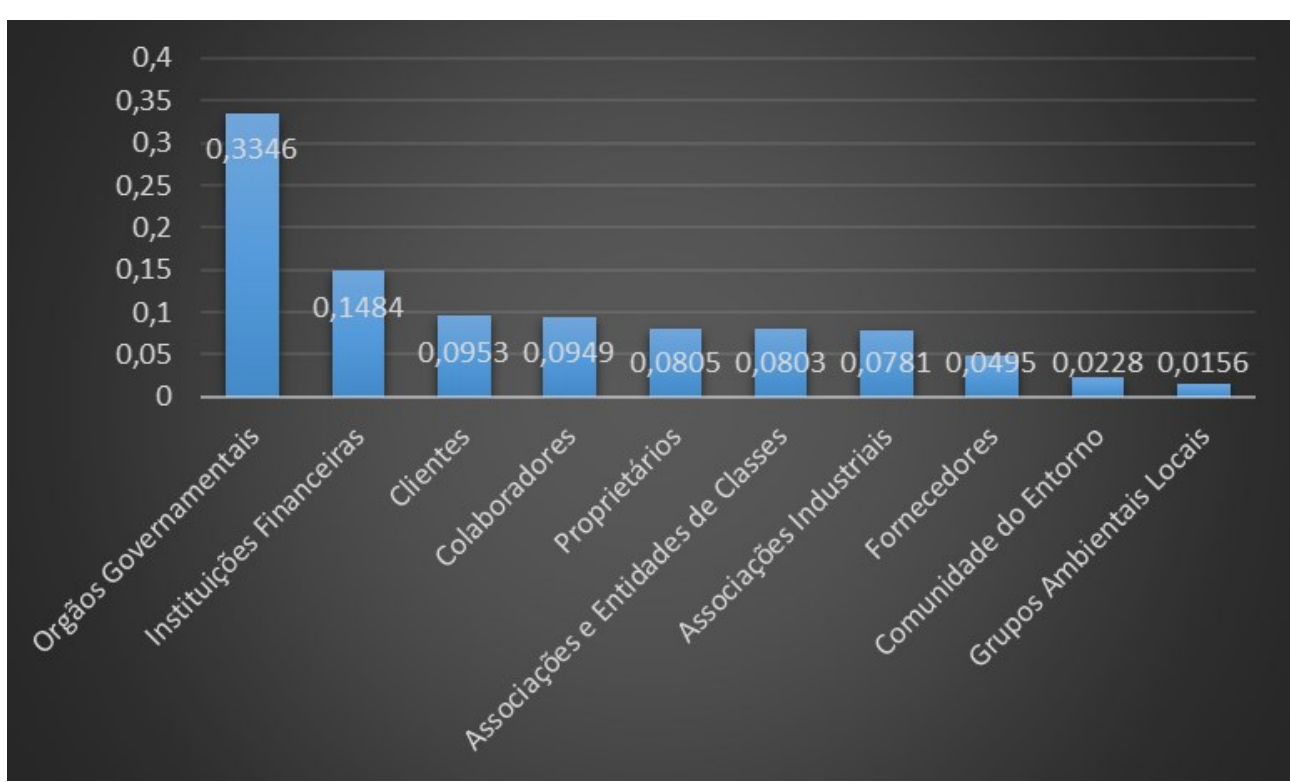

Figura 8 - Hierarquização de stakeholders

Fonte: Elaborado pelos autores

O grupo de stakeholders, que recebeu prioridade máxima (Órgãos Governamentais), se configurou 21 vezes mais importante do que o que recebeu prioridade mínima, entretanto, os stakeholders relegados a menor importância, no caso a comunidade do entorno e grupos ambientais locais, podem utilizar-se do poder de entidades governamentais para terem suas necessidades atendidas (Curzon, 2009), por meio de mecanismos como denúncias e reivindicações.

A prioridade absoluta atribuída aos órgãos governamentais pode ser, em parte, justificada pela exigência explícita contida na norma Abnt NBR ISO 14001, que prevê a identificação e o atendimento da legislação aplicável aos aspectos ambientais da organização (ABNT, 2015a). Outra razão consistiria na autoproteção da empresa contra sanções e multas (Jabbour, Santos, \& Jabbour, 2009). Em qualquer dos casos,

A importância atribuída às instituições financeiras decorre das necessidades que as empresas têm de obter fundos para suas operações, como implemento de tecnologia e aumento da infraestrutura, entre outros exemplos. As instituições financeiras, por sua vez, têm aumentado o rigor na exigência de comprovação do desempenho ambiental das empresas para liberação de fundos (Rabelo \& Lima, 2009).

Clientes exercem distintas influências sobre a organização, em razão do segmento econômico em que atuam. A indústria automobilística, por exemplo, desenvolveu um método próprio de ter atendido seus requisitos ambientais e de qualidade ao utilizar programas internos de certificação e avaliações contínuas em que o baixo desempenho é punido com deméritos e multas progressivas (Haro, 2001). A montadora, na posição de empresa focal, define o padrão ambiental mínimo da cadeia e atribui a seus fornecedores de primeira camada o mais alto nível de comprometimento aos requisitos, bem como a responsabilidade de monitorar o desempenho dos fornecedores de outras camadas.

As empresas posicionadas na primeira camada de fornecimento, conhecidas como sistemistas devem, obrigatoriamente, manter um SGA certificado e apresentar evidências de que seus subfornecedores operam em conformidade com os requisitos ambientais. Isentos da certificação ambiental, os fornecedores de segunda camada em diante comprovam sua regularidade por meio de documentação por ocasião da contratação e, eventualmente, o sistemista pode realizar auditorias periódicas, entretanto, essa sistemática está sujeita a certas deficiências.

No que concerne à regularidade documental, é preciso observar a possibilidade de que o fornecedor não tenha suas licenças ambientais renovadas após a contratação e, por tratar-se de diversos tipos de documentos com diferentes prazos de validade, o sistemista pode ter dificuldades 
para identificar esse tipo de não conformidade. Alie-se a isso o fato de que muitas empresas verificam a documentação de seus fornecedores apenas por ocasião da prestação de contas em auditorias internas, de manutenção e renovação do certificado. Outro ponto a se considerar é que, além do caráter amostral as auditorias são um evento pontual e retratam a situação presente, embora possam ser realizadas inferências a partir das evidências encontradas.

A participação dos stakeholders na governança é um meio eficiente de contornar esses e outros obstáculos para a conformidade ambiental das empresas. A necessidade de identificação dos interesses das partes interessadas na versão 2015 da norma Abnt NBR ISO 14001 é um incentivo para que as empresas e seus stakeholders estreitem suas relações e encontrem consenso no gerenciamento de seus interesses. Nesse sentido, a metodologia aplicada ao caso da empresa Alpha fortaleceu a prática da governança, uma vez que promoveu a interação entre os diferentes stakeholders e o consenso na tomada de decisão de um grupo heterogêneo.

A pesquisa de Brisolara, Silva e Cardoso (2016) evidenciou que a maioria das empresas do Rio Grande do Sul buscou certificar-se com a norma Abnt NBR ISO 14001 com foco na competitividade de mercado, isto é, as empresas possuem foco no mercado e não nas responsabilidades socioambientais. Tais responsabilidades são geradas como consequências e não como princípios sustentáveis. Isso não significa que tais ações não sejam benéficas para a sociedade, mas sim que essas ações partem de princípios economicistas e não socialmente responsáveis, como são "vendidos" no mercado para a sociedade, por meio de uma imagem verde.

Os principais benefícios relatados pelos stakeholders incluíram a capacidade de gerenciar os aspectos ambientais eficazmente, o que proporciona melhoria direta e contínua do desempenho ambiental; maior cumprimento da legislação ambiental; a prevenção da poluição; redução do risco de penalidades e litígios; melhoria da satisfação das partes interessadas e do moral dos funcionários, além de potencializar o acesso a novos mercados por meio de oportunidades de negócios com clientes ambientalmente conscientes. Isso leva tanto a custos operacionais reduzidos quanto a novas oportunidades de negócios que alavancam a posição competitiva das organizações, como constatado na pesquisa realizada por Fonseca e Domingues (2018).

\section{CONSIDERAÇÕES FINAIS}

A contribuição teórica deste estudo consistiu em um modelo de identificação e classificação dos stakeholders para o setor de transformação de material plástico, de acordo com a priorização de seus interesses em relação ao desempenho ambiental de tais indústrias. Embora a investigação seja apresentada por meio de um único caso e não seja possível generalizar os resultados, as similaridades entre as empresas do setor indicam a aplicabilidade do modelo.

Os nove tipos de stakeholders identificados foram proprietários, colaboradores, clientes, instituições financeiras, fornecedores, comunidade do entorno, associações e entidades de classe, associações industriais e órgãos governamentais.

Dentre esses, exercem menor influência os grupos dependentes das atividades e decisões da empresa, como colaboradores, associações e entidades de classe e comunidade do entorno. Grau ainda menor de influência é exercido pelos stakeholders facultativos como grupos ambientais e associações industriais. Tais constatações apontam que a tomada de decisão na empresa Alpha envolve principalmente as esferas internas de poder e sugere que os aspectos e impactos ambientais da organização são apenas comunicados aos demais stakeholders. A empresa em questão apresenta baixo potencial poluidor, no entanto, não está isenta de acidentes que possam impactar o meio ambiente.

A sociedade brasileira tem vivido experiências traumáticas resultantes das atividades empresariais, como no caso de Mariana e Brumadinho, em Minas Gerais. Esses exemplos extremos retratam a importância da participação dos stakeholders na governança ambiental das empresas, fato que a versão 2015 da norma Abnt NBR ISO 14001 incentiva ao incluir a obrigatoriedade da identificação da visão das partes interessadas na organização.

Revista de Gestão Social e Ambiental - RGSA, São Paulo, v. 13, n. 2, p. 40-57, maio/ago. 2019. 
Em termos práticos, este trabalho consiste em uma ferramenta de planejamento do SGA a ser considerado pelas organizações. Os resultados são também valiosos na medida em que facilitam aos gestores dessas empresas o delineamento do contexto da organização a partir da identificação e classificação dos interesses de suas partes interessadas. Alinhada às definições de funções, limites físicos, atividades, produtos e serviços, bem como à autoridade e capacidade de exercer controle e influência sobre os aspectos ambientais, essa estratégia possibilita o planejamento dos resultados pretendidos pelo SGA.

Sugere-se para os futuros estudos que, além de replicarem o método para definição dos stakeholders de empresas de outros segmentos econômicos, sejam incrementados com a aplicação de outras técnicas, tais como Delphi e modelagem estrutural interpretativa (Interpretative Structural Modeling [ISM]).

\section{REFERÊNCIAS}

Alberton, A. (2003). Meio ambiente e desempenho econômico-financeiro: o impacto da ISO 14001 nas empresas brasileiras. Tese de doutorado, Universidade Federal de Santa Catarina, Florianópolis, SC.

Alonso-Paul, E., \& André, F. J. (2015). Standardized environmental management systems as an internal management tool. Resource and Energy Economics 40, 85-106.

Associação Brasileira da Indústria do Plástico. (2017). Perfil 2017: Indústria brasileira de transformação de material plástico. São Paulo: Abiplast. Recuperado em 27 agosto, 2018 de http://file.abiplast.org.br/file/download/2018/Perfil_WEB.pdf.

Associação Brasileira de Normas Técnicas. (2004). NBR ISO 14001: Sistemas da gestão ambiental - requisitos com orientações para uso. Rio de Janeiro: Abnt.

Associação Brasileira de Normas Técnicas. (2015a). NBR ISO 14001: Sistemas da gestão ambiental - requisitos com orientações para uso. Rio de Janeiro: Abnt.

Associação Brasileira de Normas Técnicas. (2015b). NBR ISO 14031: Gestão ambientalavaliação de desempenho ambiental - diretrizes. Rio de Janeiro: Abnt.

Barbieri, J. C. (2007). Gestão ambiental empresarial: conceitos, modelos e instrumentos (2a ed.). São Paulo, Saraiva.

Bastos, V. D. (2009). Desafios da petroquímica brasileira no cenário global. Bndes Setorial, Rio de Janeiro, (29), 321-358.

Birou, L.M.; Green, K.W.; Inman, R. A. (2019). Sustainability knowledge and training: Outcomes and firm performance. Journal of Manufacturing Technology Management, 30 (2), 294-311.

Brisolara, L. S., Silva, V. C., \& Cardoso, N. S. (2016). Quais são os principais motivos para obter a certificação NBR ISO 14001? Um estudo com as empresas do Estado do Rio Grande do Sul. Revista de Gestão Ambiental e Sustentabilidade - GeAS, 5(2), 64-75.

Campos, L. M. S. (2012). Environmental management systems (EMS) for small companies: a study in Southern Brazil. Journal of Cleaner Production, 32, 141-148.

Carvalho, A., Mimoso, A. F., Mendes, A. N., \& Matos, H. A. (2014). From a literature review to a framework for environmental process impact assessment index. Journal of Cleaner Production, 64, $36-62$.

Creswell, J. W. (2010). Projeto de pesquisa: métodos qualitativo, quantitativo e misto (3a ed.). Porto Alegre: Artmed. 
Curzon, R. (2009). Perceptions of stakeholder engagement-just what is it really? International Journal of Green Economics, 3(3-4), 271-284.

Dhull, S., \& Narwal, M. S. (2016). Drivers and barriers in green supply chain management adaptation: a state-of-art review. Uncertain Supply Chain Management, 4(1), 61-76.

Donaldson, T., \& and Preston, L. E. (1995). The stakeholder theory of the corporation: concepts, evidence, and implications. The Academy of Management Review, 20(1), 65-91.

Duarte, T. (2009). A possibilidade da investigação a 3: reflexões sobre triangulação (metodológica). CIES e-Working paper n. ${ }^{\circ}$ 60/2009. Lisboa. Recuperado em 20 novembro, 2015 de http://www.cies.iscte.pt/destaques/documents/CIES-WP60_Duarte_003.pdf.

Dragomir, V. D. (2013). Who are the participative stakeholders? Insights from corporate social and environmental programmes. Procedia-Social and Behavioral Sciences, 75, 553-562.

Dyer, R. F., \& Forman, E. H. (1992). Group decision support with the analytic hierarchy process. Decision Support Systems, 8(2), 99-124.

Fonseca, L. M., \& Domingues, P. (2018). Exploratory research of ISO 14001:2015 transition among Portuguese Organizations. Sustainability, 10(3), 781-796.

Freeman, R. (1984). Strategic management: a stakeholder approach. Boston: Pitman.

Gomes, L. F. A. M., Araya, M. C. G., \& Carignano, C. (2004). Tomada de decisões em cenários complexos: introdução aos métodos discretos do apoio multicritério à decisão. São Paulo:

Thomson.

Haro, D. G. (2001). Sistemas da qualidade na indústria automobilística: uma proposta de autoavaliação unificada. Dissertação de Mestrado. Universidade Federal do Rio Grande do Sul, Porto Alegre, RS.

Henriques, I. \& Sadorsky, P. (1999). The relationship between environmental commitment and managerial perceptions of stakeholder importance. The Academy of Management Journal, 42 (1), 87-99.

Krueger, R. A., \& Casey, M. A. (2000). Focus groups: a practical guide for applied research, (3rd ed.). Thousand Oaks, Califórnia: SAGE Publications, Inc.

ISO. International Organization for Standardization. (2017). The ISO Survey of Management System Standard Certifications 2016. Executive Summary. Recuperado em 29 agosto, 2018 de https://www.iso.org/the-iso-survey.html.

Jabbour, C. J. C., Santos, F. C. A., \& Jabbour, A. B. L. D. S. (2009). A importância dos fatores humanos no desenvolvimento de produtos com elevado desempenho ambiental: estudo de casos. RAM - Revista de Administração Mackenzie, 10(4), 32-56.

Jabbour, C. J. C., Jugend, D., Jabbour, A. B. L. S., Gunasekaran, D., \& Latan, H. (2015). Green product development and performance of Brazilian firms: measuring the role of human and technical aspects. Journal of Cleaner Production, 87, 442-451.

Milazzo, P., Sgandurra, M. Matarazzo, A., Grassia, L., Bertino, A. (2017). The new ISO 14001:2015 standard as a strategic application of life cycle thinking. Procedia Environmental Science, Engineering and Management, 4 (2), 119-126.

Moreira, C., Bastos, V. D., Gomes, G., Costa, L. M. D., Kume, L., Magalhães, B. D. A., \& Glória, A. M. D. S. (2010). O apoio do Bndes ao setor de transformados plásticos. BNDES Setorial, Rio de Janeiro, 31, 99-145. 
Munaretto, L. F., Corrêa, H. L., \& da Cunha, J. A. C. (2013). Um estudo sobre as características do método Delphi e de grupo focal, como técnicas na obtenção de dados em pesquisas exploratórias. Revista de Administração da UFSM, 6(1), 9-24.

Oliveira, J. A., Oliveira, O. J., Ometto, A. R., Ferraudo, A. S., \& Salgado, M. H. (2016). Factors for promoting the Environmental Management System ISO 14001 for the adoption of cleaner production practices. Journal of Cleaner Production, 133, 1384-1394.

Padilha, G. M., \& Bomtempo, J. V. (1999). A inserção dos transformadores de plásticos na cadeia produtiva de produtos plásticos. Polímeros: Ciência e Tecnologia, 9(4), 86-91.

Pryshlakivsky, J., \& Searcy, C. (2013). Fifteen years of ISO 14040: a review. Journal of Cleaner Production, 57, 115-123.

Prodanov, C. C., \& Freitas, E. C. (2013). Metodologia do trabalho científico: métodos e técnicas da pesquisa e do trabalho acadêmico (2a ed.). Novo Hamburgo: Universidade Feevale.

Rabelo, M. S., \& Lima, P. V. P. S. (2009). A eficiência da inserção da variável ambiental nas instituições financeiras públicas e privadas perante o protocolo verde e os Princípios do Equador. REDE-Revista Eletrônica do Prodema, 3(1), 7-22.

Rosa, F. S., Guesser, T., Hein, N., Pftscher, E. D., \& Lunkes, R. J. (2015). Environmental impact management of Brazilian companies: analyzing factors that influence disclosure of waste, emissions, effluents, and other impacts. Journal of Cleaner Production, 96, 148-160.

Saaty, T. L. (2013). The modern science of multicriteria decision making and its practical applications: The AHP/ANP approach. Operations Research, 61(5), 1101-1118.

Saaty, T. L., \& Peniwati, K. (2013). Group decision making: drawing out and reconciling differences. Pittsburgh: RWS Publications.

Saaty, T. L., \& Shang, J. S. (2011). An innovative orders-of-magnitude approach to AHP-based mutli-criteria decision making: Prioritizing divergent intangible humane acts. European Journal of Operational Research, 214(3), 703-715.

Saaty, T. L., \& Vargas, L. G. (2012). The seven pillars of the analytic hierarchy process. In Models, methods, concepts \& applications of the analytic hierarchy process (23-40). Boston, MA: Springer.

Saaty, T. L., \& Vargas, L. G. (2013). Criteria for evaluating group decision-making methods. In Decision Making with the Analytic Network Process, 295-318. Boston, MA: Springer.

Salim, H. K., Padfield, R., Hansen, S. B., Mohamad, S. E., Yuzir, A., Syayuti, K., Tham, M. H., \& Papargyropoulo, E. (2018). Global trends in environmental management system and ISO14001 research. Journal of Cleaner Production, 170, 645-653.

Sheehan, L. R., \& Ritchie, J. B. (2005). Destination stakeholders exploring identity and salience. Annals of Tourism Research, 32(3), 711-734.

Silva, F. C., Shibao, F. Y., \& Santos, M. R. (2015). Identificação e classificação de aspectos e potenciais impactos ambientais em uma indústria do segmento de plásticos. Revista Eletrônica Gestão e Serviços, 6(1), 1084-1099.

Silva, M. F. O., Costa, S. L. M., Pereira, F. S, \& Costa, M. A. (2013). A indústria de transformação de plásticos e seu desempenho recente. Bndes Setorial, Rio de Janeiro, 38, 131-172.

Sindicato da Indústria de Material Plástico do Estado de São Paulo. (2011). Guia ambiental da indústria de transformação e reciclagem de materiais plásticos. Série $\mathrm{P}+\mathrm{L}$. São Paulo: Sindiplast. 
Recuperado em 25 julho, 2018 de http://file.sindiplast.org.br/download/guia_ambiental_internet.pdf.

Thiollent, M. (2007). Metodologia da pesquisa-ação (15a ed.). São Paulo: Cortez.

Tien, S. W., Chung, Y. C., \& Tsai, C. H. (2002). Environmental design implementation in Taiwan's industries. Environmental Impact Assessment Review, 22 (6), 685-702.

Wiengarten, F., Pagell, M., \& Fynes, B. (2013). ISO 14000 certification and investments in environmental supply chain management practices: identifying differences in motivation and adoption levels between Western European and North American companies. Journal of Cleaner Production, 56, 18-28.

Wolfe, R., \& Putler, D. (2002). How tight are the ties that bind stakeholder groups? Organization Science, 13(1), 64-80.

Wu, M. (2012). Managing stakeholders: an integrative perspective on the source of competitive advantage. Asia Social Science, 8(10), 160-172. 